\title{
TNF-alpha and IL-6 inhibit apolipoprotein A-IV production induced by linoleic acid in human intestinal Caco2 cells
}

\author{
Xiaoming $\mathrm{Li}^{1,2}, \operatorname{Min} \mathrm{Xu}^{2}$, Min Liư ${ }^{2}$, Yong $\mathrm{Ji}^{2}$ and Zongfang $\mathrm{Li}^{\mathrm{i}^{*}}$
}

\begin{abstract}
Background: Apolipoprotein A-IV (apoA-IV) is a protein mainly synthesized by enterocytes in the intestine. Its gene expression is suppressed during fasting and stimulated during active fat absorption. Chronic feeding of a high-fat (HF) diet abolishes the differential expression between fasting and fat-feeding and therefore may contribute to diet-induced obesity since apoA-IV is a potent satiety factor. It is well established that the circulating pro-inflammatory cytokines TNF- $a$ and IL-6 are increased by HF feeding.

Methods: To determine whether pro-inflammatory cytokines are involved in the diminished response of apoA-IV gene expression to fat-feeding, different concentrations of linoleic acid (LA), an important dietary fatty acid, was used to stimulate apoA-IV expression in human intestinal Caco2 cells. Cells were pre-treated with or without human recombinant TNF- $a$, IL-6 or their combination before the addition of LA. Real-time PCR and ELISA were used to detect and quantify RNA transcripts and proteins of apoA-IV and the cytokines.

Results: LA stimulated gene and protein expression of apoA-IV in a dose and time dependent manner. Pre-treatment with the cytokines for $72 \mathrm{~h}$ significantly inhibited the increased expression of apoA-IV gene and protein induced by LA. Furthermore, the cytokines, especially TNF-a, also positively up-regulate the cytokine themselves in Caco2 cells.

Conclusions: Our data indicate that the pro-inflammatory cytokines may be responsible for the reduced apoA-IV production in response to fat feeding. Because of apoA-IV's role in satiety, we propose the inhibitory effect of circulating pro-inflammatory cytokines on apoA-IV production contributes to diet-induced obesity.
\end{abstract}

Keywords: Apolipoprotein A-IV, TNF-a, IL-6, Fatty acid, Linoleic acid

\section{Background}

Obesity has reached epidemic proportions globally, and more than one-third of adults (35.7\%) in USA are obese. Being overweight or obese increases the risk of diseases including cancer, coronary heart disease, type II diabetes, hypertension and stroke. Compelling evidence has demonstrated that dietary fat intake is a major cause of obesity, diabetes, and the associated metabolic syndromes $[1,2]$.

Human apoA-IV is a $46-\mathrm{kDa}$ protein produced by enterocytes of the small intestine and its production is stimulated by fat absorption [3]. ApoA-IV is secreted in association with triacylglycerol (TG) rich chylomicron

\footnotetext{
* Correspondence: Izf2568@mail.xjtu.edu.cn

${ }^{1}$ National Local Joint Engineering Research Center of Biodiagnostics and Biotherapy, The Second Affiliated Hospital of Medical College, Xi'an Jiaotong University, Xi'an 710004, China

Full list of author information is available at the end of the article
}

particles. After entering the circulation, apoA-IV rapidly dissociates from chylomicrons and then transfers into high-density lipoproteins or becomes a lipoprotein-free fraction of the plasma in the postprandial state [4]. ApoA-IV has a number of well-established functions, including the inhibition of food intake, anti-inflammatory role, reverse cholesterol transport, and the regulation of glucose metabolism through the stimulation of insulin secretion and inhibition of hepatic gluconeogenesis [5-9]. Although the production of apoA-IV is stimulated by fat absorption, chronic ingestion of high fat (HF) feeding caused the adaptation of the intestinal apoA-IV response to lipid feeding. Weinberg et al. [10] first reported the adaptation of plasma apoA-IV in response to chronic feeding of a HF diet in humans. They observed that consumption of an HF diet for 1 week significantly 
elevated plasma apoA-IV, but after two weeks on the HF diet, the apoA-IV level returned back to baseline. Kalogeris and Painter [11] found that plasma apoA-IV increased initially by $40 \%$ in response to intra-gastric administration of fat emulsion within the first one to two days, but this was followed by the diminished responses with no increase in plasma apoA-IV levels by four days of fat feeding. Similarly, the jejunal mRNA levels and mucosal apoA-IV protein synthesis also showed time-dependent refractoriness to fat administration, suggesting both posttranslational (protein clearance) and/or pre-translation (transcriptional) adaptation of the intestinal apoA-IV production.

It is well established that circulating pro-inflammatory cytokines [e.g. tumor necrosis factor alpha (TNF- $\alpha$ ), interleukin 6 (IL-6)] are induced in obesity and these pro-inflammatory cytokines play a crucial role in the development of metabolic syndrome [12-14]. Ding et al. reported that HF diet feeding and bacteria interaction promoted TNF- $\alpha$ mRNA production and intestinal inflammation in mice; and the increase TNF- $\alpha$ preceded obesity was strongly and significantly associated with progression of obesity and development of insulin resistance [15]. Recently, Ji et al. showed that intra-duodenal infusion of fat emulsion caused mucosal mast cells activation and increased lymphatic secretion of pro-inflammatory cytokines IL-6 [16]. These observations suggest that proinflammatory cytokines derived from gut may contribute to the development of obesity and associated metabolic syndrome.

It was reported that treatment with cytokines TNF- $\alpha$ or IL-6 in cultured pig hepatocytes decreased apoA-IV mRNA levels [17], suggesting that the cytokines may contribute to dietary-induced obesity through downregulation of the important satiety signal apoA-IV expression [18]. To determine whether pro-inflammatory cytokines are involved in the attenuated response of apoA-IV to chronic HF feeding, we performed in vitro study to investigate the effect of human recombinant cytokines TNF- $\alpha$, IL- 6 or their combination on apoA-IV expression in response to the treatment of Linoleic acid (LA, an important dietary fatty acid) in cultured human intestinal Caco2 cells. Our results suggest that proinflammatory cytokines inhibit apoA-IV production induced by LA in Caco2 cells.

\section{Methods}

\section{Materials}

Linoleic acid, sodium taurocholate (TC) and other chemicals were obtained from Sigma-Aldrich (St. Louis, MO, USA). Recombinant human IL-6 (r-h-IL-6) and recombinant human TNF- $\alpha$ ( $r-h-T N F-\alpha)$ were purchased from R\&D Systems, Inc. (Minneapolis, MN, USA). Dulbecco's modified essential medium (DMEM), fetal bovine serum
(FBS) and antibiotic: antimycotic mixture were obtained from Thermo Fisher Scientific (Carlsbad, CA, USA).

\section{Cell cultures}

Caco-2 cells, obtained from the American Type Culture Collection (ATCC, Rockville, MD, USA), were grown in DMEM containing high glucose, $20 \% \mathrm{FBS}$, and a $1 \%$ antibiotic: antimycotic mixture. $70-80 \%$ confluent Caco-2 cells were plated onto 24-well plastic dishes (Becton-Dickinson Labware, Lincoln Park, NJ, USA) at initial densities of $1 \times 10^{5}$ cells/well in complete growth medium. The medium was changed every other day for 14-21 days. This procedure is known to induce differentiation of Caco-2 cells into more enterocyte-like cells [19].

\section{LA and cytokine treatment to Caco2 cells}

To prepare LA stocks $(20 \times), 20 \mathrm{mM} \mathrm{LA}$ and $10 \mathrm{mM}$ TC were mixed and stored at $-20^{\circ} \mathrm{C}$. To prepare TNF- $\alpha$ and IL-6 $(1000 \times, 10 \mathrm{mg} / \mathrm{ml})$ stocks, r-h-IL-6 and r-hTNF- $\alpha$ were dissolved in phosphate buffered saline (PBS). The differentiated Caco2 cells were incubated in growth medium with or without $20 \mathrm{ng} / \mathrm{ml}$ TNF- $\alpha$, or $20 \mathrm{ng} / \mathrm{ml} \mathrm{IL-6}$, respectively, or a mixture of the both (20 $\mathrm{ng} / \mathrm{ml} / \mathrm{each}$ ) for the indicated time, and then changed into DMEM/ high glucose/1\% FBS with or without indicated amount of LA: TC for the time indicated, with $0.5 \mathrm{mM}$ TC as vehicle control. The cells were harvested and lysed, and the total RNA was isolated.

\section{Real-time RT-PCR}

Total RNA was isolated from cells with RNeasy Mini Kit (Qiagen, Germantown, MD, USA). First-strand cDNA was synthesized from $1 \mu \mathrm{g}$ total RNA with Scripts $^{\mathrm{Tm}} \mathrm{cDNA}$ Synthesis Kit (Bio-Rad Laboratories Inc., Hercules, CA, USA) according to the manufacturer's instruction. Realtime PCR was performed using iQ SYBR Green Supermix (Bio-Rad Laboratories Inc. Hercules, CA, USA) with an iCycler iQ Detection System (icycler iQ. Multicolor Realtime PCR Detection System, Bio-Rad) and normalized to $\beta$-actin. All primers were purchased from Integrated DNA Technologies (Coralville, IA,USA). PCR primer pairs used were: human apoA-IV forward, 5' -ACCCAGCTAAGCA ACAATGC-3', and reverse, 5'-TGTCCTGGAAGAGG GTACTGA-3'; human $I l 6$ forward, 5 '-TGATGGATGCT ACCAAACTGG-3', and reverse, 5' ${ }^{\prime}$-TTCATGTACTCCA GGTAGCTATGG-3'; human Tnfo forward, 5'-TCTTC TCATT CCTGCTTGTGG-3', and reverse, 5'- GGTCT GGGCCATAGAACTGA-3'; human apoC-III forward, 5'-AGACCGCCAAGGATGCACTGA-3', and reverse, 5'-TCTGACCTCAGGGTCCAAATCC-3'; $\beta$ Actin forward, 5' -TTGCTGACAGGAT-GCAGAAGGAGA-3', and reverse, 5' -TCAGTAACAGTCCGCCTAGAAGCA-3'. 


\section{Enzyme linked immunosorbent assay (ELISA)}

ELISA was performed using Human ApoA-IV ELISA Kit from Millipore Corporation (Billerica, MA, USA), Human IL-6 and Human TNF- $\alpha$ ELISA Kits from RayBiotech (Norcross, GA, USA) according to the protocol provided by the manufacturer. The culture mediums collected from the cells treated with LA with or without cytokines were used to measure the proteins released from the cells by ELISA.

\section{Statistics}

Data represent Mean \pm SE from three or four wells in each experiment of at least two independent cell culture experiments. Significance of differences was determined by one-way ANOVA or two-way ANOVA followed by Tukey test method. $\mathrm{P}$ value less than 0.05 was considered significant.

\section{Results}

LA stimulates apoA-IV gene expression in $\mathrm{Caco} 2$ cells

To induce gene expression of apoA-IV in Caco2 cells, the medium of differentiated Caco2 cells was supplemented with LA mixed with TC in the indicated dose and time, as described previously [19]. First, we studied the effect of different concentrations $(0.25,0.5,1.0 \mathrm{mM})$ of LA on apoA-IV gene expression after $24 \mathrm{~h}$ incubation. As shown in Figure 1A, $0.25 \mathrm{mM}$ of LA was able to enhance apoA-IV gene expression by 1.31 fold, compared with TC vehicle control, although there was no statistically significant difference. $0.5 \mathrm{mM}$ of LA significantly increased apoA-IV mRNA level by 3.3 fold, and $1 \mathrm{mM}$ of LA by 4.42 fold. Second, we determined the time course of apoA-IV gene expression of Caco2 cells after incubation with $1 \mathrm{mM}$ LA for various times $(3,6,12$, and $24 \mathrm{~h}$ ). As shown in Figure 1B, apoA-IV mRNA level started to increase by 2.34 fold when incubated with LA for $12 \mathrm{~h}$, and increased by 4.42 fold at $24 \mathrm{~h}$, compared with that treated with vehicle controls. Finally, to test whether the apoA-IV protein is also changed with its mRNA levels, we measured the apoA-IV protein levels in the culture medium after the treatment with different amount of LA for $24 \mathrm{~h}$ incubation. As presented in Figure 1C, $0.25 \mathrm{mM}$ LA surprisedly showed a maximum effect on apoA-IV protein production, which was stronger than $0.5 \mathrm{mM}$ LA. However, when LA dose increased to $1 \mathrm{mM}$, its effect on apoA-IV was almost gone. These data indicate that LA up-regulates both apoA-IV mRNA and protein levels in dose-dependent manner, but in different pattern, in the Caco2 cells.

\section{Cytokines inhibit apoA-IV production induced by LA}

It has been reported that cytokine IL- 6 and TNF- $\alpha$ reduced apoA-IV mRNA levels in pig hepatocytes [17]. To determine whether long time exposure to TNF- $\alpha$ and
IL-6 also affects apo $A-I V$ gene expression induced by LA in Caco2 2 cells, the differentiated Caco 2 cells were pretreated with r-h-TNF $\alpha$ and r-h-IL6 for $72 \mathrm{~h}$, followed by incubation with or without $1 \mathrm{mM}$ LA for $24 \mathrm{~h}$. As shown in Figure 2A, the cytokines did not affect apoA$I V$ mRNA in the cells without LA treatment. However, pre-treatment with the combination of these two cytokines significantly attenuated LA-induced increase of mRNA levels (Figure 2A) and apoA-IV protein secretion (Figure 2B). To further determine which cytokine, TNF$\alpha$ or IL-6, exerts the inhibitory effect, we pre-incubated the cells with either TNF- $\alpha$ or IL-6, respectively, followed by the LA treatment. We found that TNF- $\alpha$ significantly attenuated the increased levels of both apoA-IV mRNA (Figure 2A) and protein (Figure 2B) induced by LA, whereas IL-6 had no such effect on apoAIV mRNA level (Figure 2A), but significantly attenuated apoA-IV protein level induced by $0.25 \mathrm{mM}$ LA (Figure 2B). Furthermore, TNF- $\alpha$ and IL-6 themselves decreased apoA-IV protein levels (Figure 2B), but not apoA-IV mRNA levels (Figure 2A). These data indicate that both TNF- $\alpha$ and IL- 6 inhibit the stimulatory effect of LA on apoA-IV production.

\section{Effects of LA and cytokines on apoC-III gene expression in Caco2 cells}

ApoA-IV is a member of the apoA-I/C-III/A-IV gene cluster. It was reported previously that intestinal expression of apoA-IV and apoC-III is coordinately regulated by dietary lipid in newborn swine [20]. To test whether LA specifically stimulates apoA-IV expression in Caco-2 cells, we measured the mRNA level of apoC-III in the presence of LA or/and the cytokines, and determined whether the pre-treatment of cytokines affects the responses of apoC-III to LA. As shown in Figure 2C, treatment with $1 \mathrm{mM} \mathrm{LA}$ alone or pre-treatments with cytokines (IL-6, TNF- $\alpha$, or their combination) did not significantly affect apoC-III gene expression in the Caco2 cells. Interestingly, TNF- $\alpha$, but not IL-6, significantly decreased apoC-III expression in the Caco-2 cells (Figure 2C). These observations indicate that LA specifically stimulates apoA-IV expression in Caco-2 cells. In addition, different from the changes in apoA-IV mRNA levels, apoC-III mRNA was significantly decreased by TNF- $\alpha$ at the condition without LA stimulation.

\section{LA stimulates productions of 116 and Tnfa}

It has been reported that long-chain fatty acid, e.g. the LA, can enhance Il6 production in rat intestinal epithelial cells [21]. To determine whether LA is able to affect gene expressions of endogenous cytokines IL-6 and TNF- $\alpha$ in the Caco2 cells, we measured mRNA levels of Il6 and Tnfo at the indicated times of LA treatment from $\mathrm{Caco} 2$ cells and their proteins released from the 

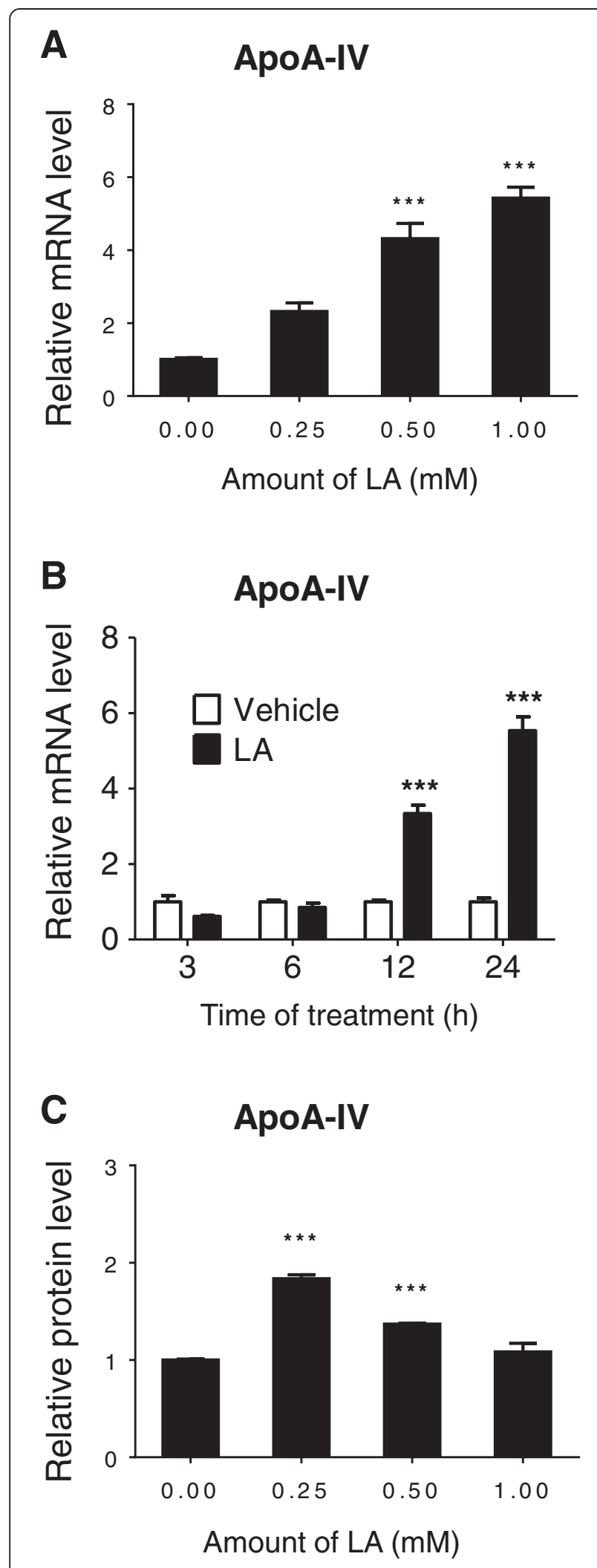

Figure 1 LA induced apoA-IV gene expression in Caco2 cells. Differentiated $\mathrm{Caco} 2$ cells were supplemented with or without different amount of LA for $24 \mathrm{~h}$ (A) or for the indicated time with $1 \mathrm{mM}$ LA (B) up to $24 \mathrm{~h}$. The apoA-IV mRNA levels were measured by real time RT-PCR. The levels of apoA-IV protein released into culture medium from the cells were measured by ELISA (C). ${ }^{* * *} P<0.001$ vs. TC vehicle control.

cells after the treatment with different amount of LA for $24 \mathrm{~h}$. We found that the LA stimulated Tnfo and Il6 gene expressions sooner than apoA-IV expression. The mRNA level of $I l 6$ started to increase by 1.03 fold after $3 \mathrm{~h}$ treatment, although the difference is not statistically significant, and then reached to 3.4 fold increase at $6 \mathrm{~h}$ (Figure 3A). The mRNA level of Tnfo was significantly increased sooner than $I l 6 \mathrm{mRNA}$ and it reached to 3.57 fold at $2 \mathrm{~h}, 3.52$ fold increases at $3 \mathrm{~h}$ and then reduced to 1.4 fold increases by $6 \mathrm{~h}$ (Figure 3B). It is noteworthy that the pattern of Tnfo gene expression was similar to Il6, and all dropped back to basal level at $12 \mathrm{~h}$, but $I l 6$ start to express again at $24 \mathrm{~h}$ post-treatment of LA (Figure 4A), which could be positive feedback regulation from the other factors, such as TNF- $\alpha$, as a result from LA stimulation. We also measured their protein levels and found that $0.5 \mathrm{mM}$ LA had the maximum effects on both IL- 6 and TNF- $\alpha$ protein levels although $0.25 \mathrm{mM}$ and $1 \mathrm{mM}$ LA increased the cytokine protein productions, too (Figure $3 \mathrm{C}$ and D).

Cytokines positively regulate their own gene expression To determine whether the cytokines also affect their own expression, the mRNAs of Il6 and Tnfo were measured in the Caco-2 cells treated with or without the cytokines and/or with LA. As shown in Figure 4, no change in Il6 mRNA levels was found in the cells when these two cytokines were treated individually or their combination without LA treatment. However, LA significantly stimulated Il6 gene expression, which was significantly attenuated by pre-treatment of IL- 6 , but not by TNF- $\alpha$. Additionally, pre-treatment with the combination of IL-6 and TNF- $\alpha$ led to further increase of Il6 gene expression in those cells. Similarly, treatment with TNF- $\alpha$, especially the combination of IL- 6 and TNF- $\alpha$, stimulated Tnfo gene expression in the Caco-2 cells either with or without LA treatment. These data indicate that the cytokines, especially TNF- $\alpha$, could positively up-regulate their own gene expression in Caco-2 cells.

\section{Discussion}

ApoA-IV is produced dominantly in the gut and has many physiological functions which include satiety, regulation of glucose metabolism, reverse cholesterol transport and also anti-inflammation $[6,8,9,22]$. Therefore, the reduced apoA-IV production in response to 

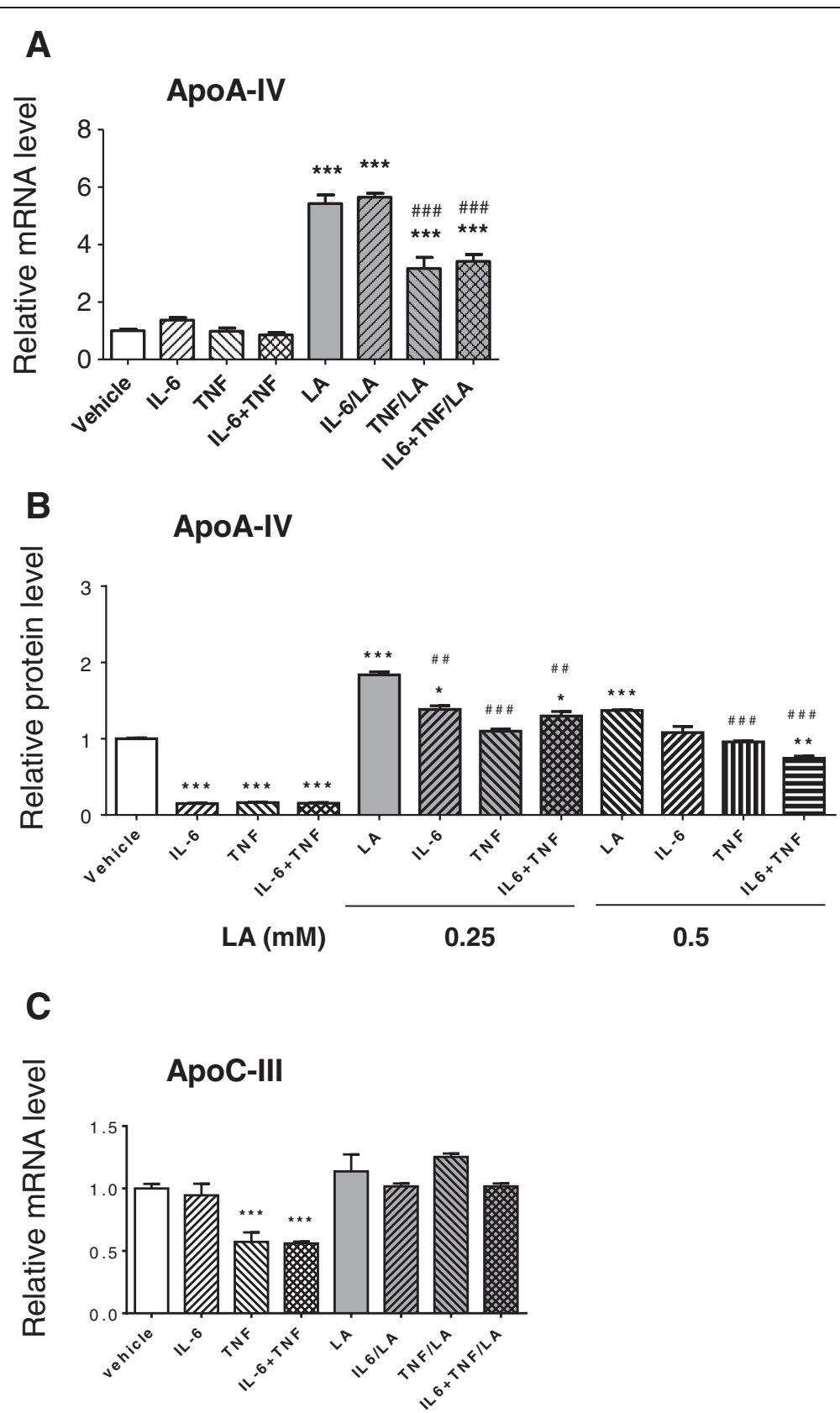

Figure 2 Effects of cytokines on apoA-IV and apoC-III gene expression. (A) Effects of LA and cytokines on apoA-IV gene expression. Differentiated Caco 2 cells were pre-treated with or without r-h-TNF-a $(20 \mathrm{ng} / \mathrm{ml})$ or r-h-lL-6 $(20 \mathrm{ng} / \mathrm{ml})$ or the combination of these two cytokines for $72 \mathrm{~h}$ before changing into medium with or without $1 \mathrm{mM} \mathrm{LA}$ for $24 \mathrm{~h}$. (B) Effects of LA and cytokines on apoA-IV protein secretion. Differentiated Caco2 cells were pre-treated with or without r-h-TNF-a $(20 \mathrm{ng} / \mathrm{ml})$ or r-h-lL-6 $(20 \mathrm{ng} / \mathrm{ml})$ or the combination of these two cytokines for $72 \mathrm{~h}$ before changing into medium with or without 0.25 or $0.5 \mathrm{mM}$ LA for $24 \mathrm{~h}$. The apoA-IV proteins in culture medium secreted from the cells were measured by ELISA. (C) Effects of LA and cytokines on apoC-III expression. The samples were processed at the same ways described at (A). The mRNA levels of both apoA-IV and apoC-III were measured by real time RT-PCR. ${ }^{*} P<0.05$, ${ }^{* *} P<0.01,{ }^{* * *} P<0.001$ vs. vehicle control; and ${ }^{\# \#} P<0.01{ }^{\# \# \#} P<0.001$ vs. LA.

active lipid absorption after chronic HF diet-feeding has been implicated in the diet-induced obesity and metabolic disorders. The purpose of this study was to test the hypothesis that the inflammatory cytokines expressed and released during chronic HF feeding potentially play an important role in this reduced apoA-
IV response to fat absorption. Linoleic acid (LA) is an important dietary fatty acid and a major component in many HF diets or the lipids that have been used to induce apoA-IV production [11,23].

Caco-2 cells, a human colon carcinoma cell line, have been widely used as a model to study intestinal epithelial 


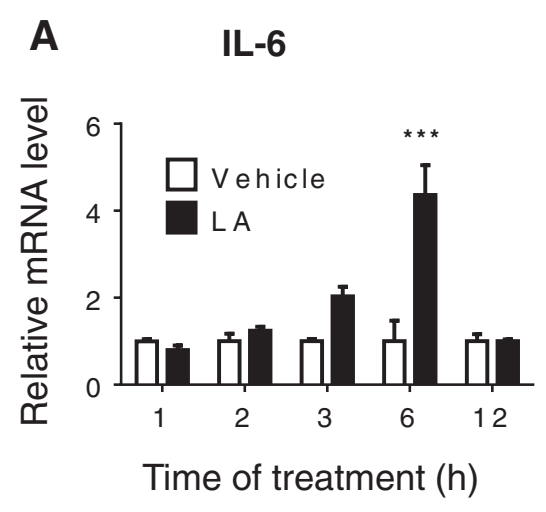

B

TNF- $\alpha$

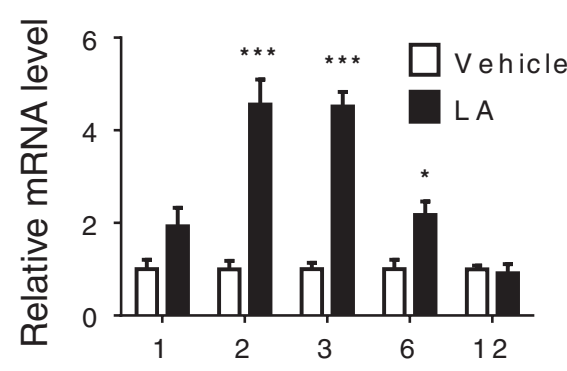

Time of treatment $(\mathrm{h})$

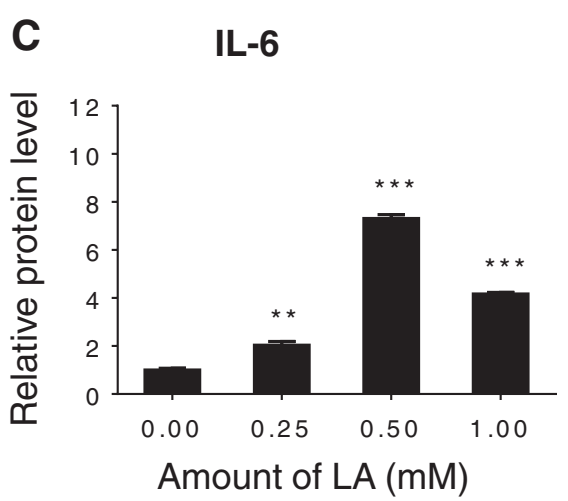

D

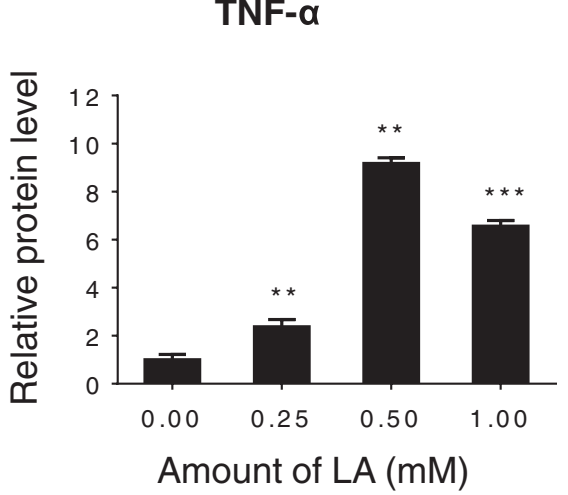

Figure 3 LA stimulated gene expression of $\mathbf{I l 6}$ and Tnfa in Caco2 cells. Differentiated Caco2 cells were supplemented with or without 1 mM LA for the indicated times for mRNA measurement or with different amount of LA for $24 \mathrm{~h}$ for protein measurement. The mRNA levels of $/ 16$ and Tnfa were measured by real time RT-PCR (A and B). Their proteins from culture medium were measured by ELISA (C and D). ${ }^{*} P<0.05,{ }^{*} P<0.01$, *** $P<0.001$ vs. vehicle control.

cell metabolism, including lipids and lipoproteins [19,24-27]. However, it has not been tested previously whether LA stimulates apoA-IV expression in those cells. With different dose of LA and varying incubation times with the differentiated $\mathrm{Caco} 2$ cells, for the first time, we found that apoA-IV gene expression and protein secretion was significantly increased in response to LA stimulation. Notably, apoA-IV production was significantly enhanced with lower amount of LA $(0.25 \mathrm{mM})$ stimulation, but high dose of LA $(1 \mathrm{mM})$ failed to increase apoA-IV protein production, although apoA-IV mRNA was significantly increased with this amount of LA from $12 \mathrm{~h}$ to $24 \mathrm{~h}$. It was wellknown that fat induces both apoA-IV synthesis and secretion from the gut, but up to now, its molecular mechanism is not clear. Our observations that apoAIV mRNA level was increased with the increase of LA amount, but protein secretion of apoA-IV could not induced by a higher amount of LA, indicating that higher amount of LA may activate or induce other related factors, e.g. IL- 6 and TNF- $\alpha$, which can impact apoA-IV's translation and the stability.
ApoA-IV is a member of a closely linked apoA-I/C-III/ $A-I V$ gene cluster, a target for acute phase proteins. A coordinately regulation of apoC-III and apoA-IV expression by lipids has been previously described [20]. However, it is also reported that the regulation of the members of this cluster by fat and inflammatory processes in the gut is not shared by all members of the cluster, e.g. neither the magnitude of response to the stimuli, nor the behavior of apoA-IV and apoC-III was similar [17]. Our data showed no difference in apoC-III gene expression in the cultured $\mathrm{Caco} 2$ cells treated with LA, IL-6 or the both together. In contrast, significant change in apoA-IV gene expression was observed when the Caco2 cells were exposed to the same cytokines. These results indicate a loss of the coordinated response reported previously in the animals [20], and suggest a complex interplay of transcription factors modulated by species-specific signaling pathways in response to a specific stimuli.

Our data also showed that LA not only induced apoA$I V$ gene expression, but also stimulated TNF- $\alpha$ and IL-6 secretion in $\mathrm{Caco} 2$ cells. Circulating cytokines, such as 


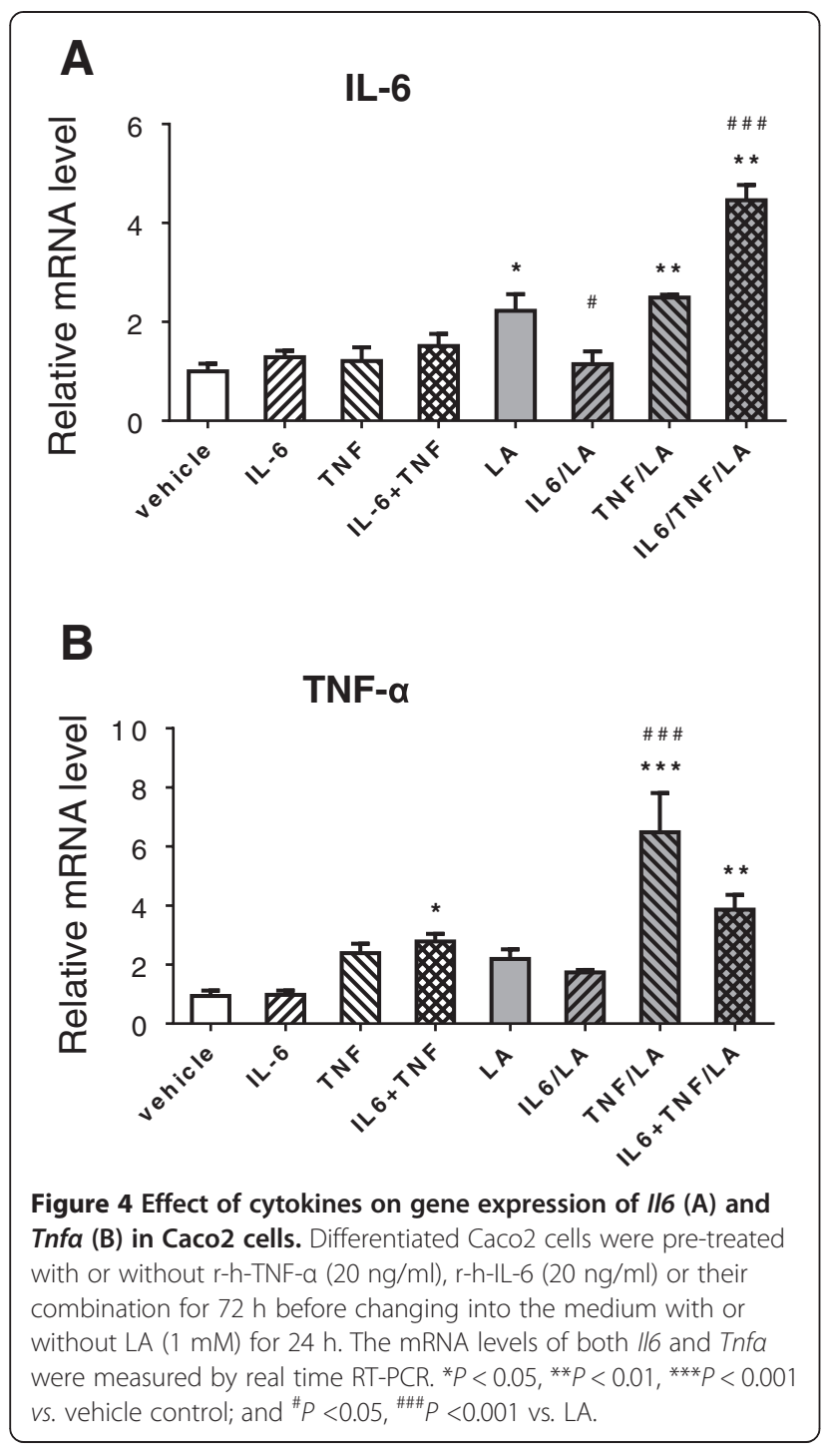

TNF- $\alpha$ or IL- 6 , have been shown to be elevated in obese humans $[28,29]$ and this could be reversed with weight loss [30]. While the mechanisms underlying obesityassociated inflammation are not fully understood, a number of studies suggested that the inflammation may derive from the accumulation of activated macrophages within adipose tissue, liver, and the enlarged adipocytes in obese animals and humans $[14,31,32]$. Recent studies $[15,16]$ suggest that 1$)$ the gastrointestinal tract is another and early source of inflammation associated with diet, 2) the onset of intestinal inflammation precedes diet-induced increases in body weight, fat mass, as well as insulin resistance, and 3) the degree of TNF- $\alpha$ induction strongly correlates with diet-induced increases in weight, adiposity, plasma glucose, and insulin. Our data that LA-induced elevation of both TNF- $\alpha$ and $I L-6$ mRNAs and of protein levels in Caco2 cells further support the concept that inflammatory cytokines released from the gut induced by fatty acid is the early source of inflammation associated with the development of obesity and/or metabolic disorders because TNF- $\alpha$ and IL-6 are widely used as early biomarkers of inflammation of insulin resistance and the obesity relative diseases.

It has been reported that TNF- $\alpha$ activates NF- $\mathrm{kB}$ and other inflammatory pathways $[33,34]$. As we described above, LA not only induced apoA-IV gene expression but also stimulated the gene expression and secretion of the cytokines. In addition, consistent with previous studies, TNF- $\alpha$ and IL-6, especially TNF- $\alpha$, are further stimuli in the expression of the cytokines in the Caco2 cells, and enhance the effect of LA on these cytokines.

It rapidly became clear that early proinflammatory effects of HF diet, such as elevated TNF- $\alpha$, could serve as a trigger for subsequent inflammation or insulin resistance through activating NF-kB and other inflammatory pathways involved in the etiology of insulin resistance and Type 2 diabetes. In addition to regulating metabolic homeostasis and intracellular signaling pathways that are well-established metabolic functions, inflammatory cytokines can impact on release of gut hormones such as glucagon-like peptide 2 (GLP-2) [15]. Our observations that these two cytokines reduced apoA-IV production, but not apoA-IV gene expression, imply that these cytokines' inhibitory effects on apoA-IV not only occur at transcriptional levels but also at translational or posttranslational levels.

Pro-inflammatory molecules released by intestines, adipose and liver enter the circulation to influence the expression of apoA-IV at the gut. Our data that exogenous cytokines decreased apoA-IV production induced by LA support our hypothesis that pro-inflammatory cytokines are involved in reducing apoA-IV responses to fat feeding. These results support the notion that cytokines induction by chronic fat feeding is responsible for the blunted apoA-IV production normally stimulated by active fat absorption.

\section{Conclusions}

Our study demonstrates that fatty acid LA induces apoA-IV gene expression and, at the same time, promotes inflammatory cytokines expression in the Caco2 cells. After chronic HF diet-feeding, constant and increased cytokine release resulted from positive feedback regulation of the cytokines suppresses apoA-IV production in response to fat absorption. Because of apoA-IV's roles in the regulation of food intake, lipid absorption and glucose metabolism, the correlation between the local/circulating pro-inflammatory cytokines and apoA-IV production contributes to diet-induced obesity and the associated disorders. 


\section{Abbreviations}

LA: Linoleic acid; ApoA-IV: Apolipoprotein A-IV; TNF-a: Tumor necrosis factor alpha; IL-6: Interleukin-6; HFD: High fat diet; TG: Triacylglycerol; ApoC-III: Apolipoprotein C-III.

\section{Competing interests}

The authors declare that they have no competing interests.

\section{Authors' contributions}

$\mathrm{XL}$ carried out the main body of this work and prepared the manuscript. MX performed the experiments. ML and YJ participated in the preparation and revision of the manuscript. ZF participated in designing and cooperating. All authors have read and approved the final manuscript.

\section{Acknowledgements}

We thank Dr. Patrick Tso (Department of Pathology and Laboratory Medicine, University of Cincinnati, Ohio, USA), who was involved in designing and revising the manuscript critically. This work was supported in part by grants for Dr. Patrick Tso from the NIH DK 59630, DK 92138, and DK 76928 and for Min Liu from the NIH DK95440 and DK92779.

\section{Author details}

${ }^{1}$ National Local Joint Engineering Research Center of Biodiagnostics and Biotherapy, The Second Affiliated Hospital of Medical College, Xi'an Jiaotong University, Xi'an 710004, China. ${ }^{2}$ Department of Pathology and Laboratory Medicine, University of Cincinnati, Cincinnati 45237-0507, USA.

Received: 4 July 2014 Accepted: 11 March 2015

Published online: 22 March 2015

\section{References}

1. Calder PC, Ahluwalia N, Brouns F, Buetler T, Clement K, Cunningham K, et al. Dietary factors and low-grade inflammation in relation to overweight and obesity. Br J Nutr. 2011;106:S1-+.

2. Kuller LH. Dietary fat and chronic diseases: epidemiologic overview. J Am Diet Assoc. 1997;97:S9-15.

3. Bisgaier $C L$, Sachdev OP, Megna L, Glickman RM. Distribution of apolipoprotein-a-Iv in human-plasma. J Lipid Res. 1985;26:11-25.

4. Weinberg RB. Apolipoprotein A-IV polymorphisms and diet-gene interactions. Curr Opin Lipidol. 2002;13:125-34.

5. Liu M, Doi T, Shen L, Woods SC, Seeley RJ, Zheng SQ, et al. Intestinal satiety protein apolipoprotein AIV is synthesized and regulated in rat hypothalamus. Am J Physiol Regul Integr Comp Physiol. 2001;280:R1382-7.

6. Qin XF, Swertfeger DK, Zheng SQ, Hui DY, Tso P. Apolipoprotein AIV: a potent endogenous inhibitor of lipid oxidation. Am J Physiol Heart Circ Physiol. 1998:43:H1836-40.

7. Recalde D, Ostos MA, Badell E, Garcia-Otin AL, Pidoux J, Castro G, et al. Human apolipoprotein A-IV reduces secretion of proinflammatory cytokines and atherosclerotic effects of a chronic infection mimicked by lipopolysaccharide. Arterioscler Thromb Vasc Biol. 2004:24:756-61.

8. Wang F, Kohan AB, Kindel TL, Corbin KL, Nunemaker CS, Obici S, et al. Apolipoprotein A-IV improves glucose homeostasis by enhancing insulin secretion. Proc Natl Acad Sci U S A. 2012;109:9641-6.

9. Li XM, Xu M, Wang F, Kohan AB, Haas MK, Yang Q, et al. Apolipoprotein A-IV reduces hepatic gluconeogenesis through nuclear receptor NR1D1. J Biol Chem. 2014;289:2396-404.

10. Weinberg RB, Dantzker C, Patton CS. Sensitivity of serum apolipoprotein A-IV levels to changes in dietary-Fat content. Gastroenterology. 1990;98:17-24.

11. Kalogeris TJ, Painter RG. Adaptation of intestinal production of apolipoprotein A-IV during chronic feeding of lipid. Am J Physiol Regul Integr Comp Physiol. 2001;280:R1155-61.

12. Hotamisligil GS. Inflammation and metabolic disorders. Nature. 2006;444:860-7.

13. Lumeng CN, Bodzin JL, Saltiel AR. Obesity induces a phenotypic switch in adipose tissue macrophage polarization. J Clin Invest. 2007:117:175-84.

14. Park EJ, Lee JH, Yu GY, He GB, Ali SR, Holzer RG, et al. Dietary and genetic obesity promote liver inflammation and tumorigenesis by enhancing IL-6 and TNF expression. Cell. 2010;140:197-208.

15. Ding SL, Chi MM, Scull BP, Rigby R, Schwerbrock NMJ, Magness S, et al. High-Fat Diet: Bacteria Interactions Promote Intestinal Inflammation Which Precedes and Correlates with Obesity and Insulin Resistance in Mouse. Plos One. 2010;5:e1219.
16. Ji Y, Sakata Y, Yang Q, Li XM, Xu M, Yoder S, et al. Activation of rat intestinal mucosal mast cells by fat absorption. Am J Physiol Gastrointest Liver Physiol. 2012;302:G1292-300.

17. Navarro MA, Carpintero R, Acin S, Arbones-Mainar J, Calleja L, Carnicer R, et al. Immune-regulation of the apolipoprotein A-I/C-III/A-IV gene cluster in experimental inflammation. Cytokine. 2005;31:52-63.

18. Liu M, Shen L, Liu Y, Tajima D, Sakai R, Woods SC, et al. Diurnal rhythm of apolipoprotein A-IV in rat hypothalamus and its relation to food intake and corticosterone. Endocrinology. 2004;145:3232-8.

19. Luchoomun J, Hussain MM. Assembly and secretion of chylomicrons by differentiated Caco-2 cells - Nascent triglycerides and preformed phospholipids are preferentially used for lipoprotein assembly. J Biol Chem. 1999:274:19565-72.

20. Black DD, Wang H, Hunter F, Zhan R. Intestinal expression of apolipoprotein A-IV and C-III is coordinately regulated by dietary lipid in newborn swine. Biochem Biophys Res Commun. 1996;221:619-24.

21. Yoshida H, Miura S, Kishikawa H, Hirokawa M, Nakamizo H, Nakatsumi RC, et al. Fatty acids enhance GRO/CINC-1 and interleukin-6 production in rat intestinal epithelial cells. J Nutr. 2001;131:2943-50.

22. Qin XF, Tso P. The role of apolipoprotein AIV on the control of food intake. Curr Drug Targets. 2005;6:145-51.

23. Liu M, Shen L, Liu Y, Woods SC, Seeley RJ, Alessio DD, et al. Obesity induced by a high-fat diet downregulates apolipoprotein A-IV gene expression in rat hypothalamus. Am J Physiol Endocrinol Metab. 2004;287:E366-70.

24. Dashti N. Synthesis and secretion of nascent lipoprotein particles. Prog Lipid Res. 1991;30:219-30.

25. Field FJ, Born E, Mathur SN. Triacylglycerol-rich lipoprotein cholesterol is derived from the plasma membrane in $\mathrm{CaCo}-2$ cells. J Lipid Res. 1995;36:2651-60.

26. Hussain MM, Kancha RK, Zhou ZY, Luchoomun J, Zu HY, Bakillah A. Chylomicron assembly and catabolism: role of apolipoproteins and receptors. Biochim Biophys Acta, Lipids Lipid Metab. 1996;1300:151-70.

27. Levy E, Mehran M, Seidman E. Caco-2 cells as a model for intestinal lipoprotein synthesis and secretion. FASEB J. 1995;9:626-35.

28. Kern PA, Ranganathan S, Li CL, Wood L, Ranganathan G. Adipose tissue tumor necrosis factor and interleukin-6 expression in human obesity and insulin resistance. Am J Physiol Endocrinol Metab. 2001;280:E745-51.

29. Syrenicz A, Garanty-Bogacka B, Syrenicz M, Gebala A, Walczak M. Low-grade systemic inflammation and the risk of type 2 diabetes in obese children and adolescents. Neuroendocrinol Lett. 2006;27:453-8.

30. Dandona P, Weinstock R, Thusu K, Abdel-Rahman E, Aljada A, Wadden T. Tumor necrosis factor-alpha in sera of obese patients: fall with weight loss. J Clin Endocrinol Metab. 1998;83:2907-10.

31. Weisberg SP, McCann D, Desai M, Rosenbaum M, Leibel RL, Ferrante AW. Obesity is associated with macrophage accumulation in adipose tissue. J Clin Invest. 2003;112:1796-808.

32. Xu HY, Barnes GT, Yang Q, Tan Q, Yang DS, Chou CJ, et al. Chronic inflammation in fat plays a crucial role in the development of obesity-related insulin resistance. J Clin Invest. 2003;112:1821-30.

33. Arkan MC, Hevener AL, Greten FR, Maeda S, Li ZW, Long JM, et al. IKK-beta links inflammation to obesity-induced insulin resistance. Nat Med. 2005;11:191-8

34. Yuan M. Reversal of obesity- and diet-induced insulin resistance with salicylates or targeted disruption of Ikk beta (vol 293, pg 1673, 2001). Science. 2002;295:277.

\section{Submit your next manuscript to BioMed Central and take full advantage of:}

- Convenient online submission

- Thorough peer review

- No space constraints or color figure charges

- Immediate publication on acceptance

- Inclusion in PubMed, CAS, Scopus and Google Scholar

- Research which is freely available for redistribution 